\title{
Left Ventricular Diastolic Dysfunction and Obesity: A Systematic Review and Meta-analysis of Echocardiographic Studies
}

\author{
Luo Liyun, Li Songbiao*, Wang Chengshan, Lin Xiufang \\ Department of Cardiology, the Fifth Affiliated Hospital of Sun Yat-Sen University, China
}

Copyright $(2016$ by authors, all rights reserved. Authors agree that this article remains permanently open access under the terms of the Creative Commons Attribution License 4.0 International License

\begin{abstract}
Objective: Left ventricular diastolic dysfunction is a common cardiac condition in obese individuals. An updated review and meta-analysis focusing on this issue is lacking, we analyzed the literatures in order to conduct comprehensive information on the left ventricular diastolic function changes, as assessed by echocardiography, associated to obesity. Methods: A literature search using the keywords 'left ventricular diastolic dysfunction', 'diastolic dysfunction', 'obesity', 'obese' 'body mass index' and 'echocardiography' was performed in order to identify relevant papers. Full articles published in English in peer-reviewed journals in past 20 years reporting studies in adult obese individuals were considered. Results: A total of 11 studies including 5171 participants (2764 adults are obese patients) were considered. Obesity was defined as a BMI of $\geq 30 \mathrm{~kg} / \mathrm{m}^{2}$.Meta-analysis of selected 11 studies (2764 obesity subjects and 2407 normal weight) found that there is no difference of peak late diastolic mitral flow velocity (A) and deceleration time of early diastolic flow wave (DT) between the two groups, while other related parameters such as peak late diastolic mitral flow velocity (A) and E/A ratio, isovolumic relaxation time (IVRT), early diastolic myocardial velocities $\left(E^{\prime}\right)$ and $E / E^{\prime}$ ratio are significant different between obese individuals and non-obese controls, the values of A, IVRT and E/E' were higher in obesity group compared with that of in control group, while the values of $\mathrm{E} / \mathrm{A}$ ratio and $\mathrm{E}^{\prime}$ were lower in obesity group. Conclusions: Our study shows that left ventricular diastolic dysfunction is present in obese population, Body mass index was found as a significant predictor for DD.
\end{abstract}

Keywords Left Ventricular Diastolic Dysfunction, Body Mass Index, Obese, Echocardiography

\section{Introduction}

Obesity is a major public health epidemic and it has been increasing at alarming rates worldwide in all age groups [1]. Substantial epidemiologic data indicated that obesity is associated with significant alteration in left ventricular structure and function and it is an independent predictor of most cardiovascular morbidity and mortality, as well as overall mortality in populations [2]. Left ventricular diastolic dysfunction (DD) is a common cardiac condition and contributes significantly to the future development of heart failure with preserved systolic function in obese patients [3-4]. Several studies have evaluated the relation between body mass index (BMI) and left ventricular DD, BMI was found as a significant predictor for DD even after adjusting for age, mean arterial pressure and left ventricle mass index [5-6]. However, the associations of these indices with obesity reported in previous studies have been variable [7]. Furthermore, parameters used to evaluate left ventricular diastolic function were inconsistent in previous reports. Therefore, we analyzed the studies published in the past 20 years focusing on this issue in order to provide a review and meta-analysis on the prevalence of left ventricular DD in obese individuals.

\section{Methods}

\subsection{Selection of Studies}

Medical literature was reviewed in order to identify all articles evaluating left ventricular DD in obese individuals. A computerized search was performed using PubMed, OVID and EMBASE databases from 1 January 1995 up to 31 September 2015.The articles were identified by the following keywords: 'left ventricular diastolic dysfunction', 'diastolic dysfunction', 'obesity', 'obese' ' body mass index' and 'echocardiography'. Checks of the reference lists of selected papers and pertinent reviews complemented the electronic search. Data had been extracted by two independent investigator, we did not contact authors to 
provide missing information. Information about publication time, country, study types, population characteristics, age, number of study object, echocardiography parameters related to left ventricular DD and echocardiograph assessment tools were collected. Disagreements were resolved by discussion between two investigators.

Inclusion criteria were: (1)Full articles published in English in peer-reviewed journals from 1 January 1995 up to 31 September 2015; (2)Studies reporting data on left ventricular DD assessed by conventional transthoracic echocardiography and(or) tissue Doppler imaging(TDI); (3) Studies including an least 30 adult individuals; (4) Obesity was defined as a BMI of $\geq 30 \mathrm{~kg} / \mathrm{m}^{2}$;

\subsection{Evaluation of Study Quality}

The Newcastle-Ottawa quality assessment scale (NOS) was used to assess the quality of the included studies [8].NOS consists of three categories: selection (adequate case definition, representativeness of cases, selection of controls, definition of controls); Comparability (comparability of cases and controls on the basis of the design or analysis ); Exposure(Ascertainment of exposure, same method of ascertainment for cases and controls, non-response rate). There are 9 question in this scale and the highest score is 9 points, The literatures were regarded as high quality research if the score is more than 6 points.

\subsection{Statistical Analysis}

Our systematic review and meta-analysis followed the recommendations of the Preferred Reporting Items for Systematic Reviews and Meta-analyses (PRISMA) collaboration [9]. Our primary objective was to evaluate the association between obesity and left ventricular DD. Statistical heterogeneity was tested with Cochran's Q test and quantified with the $\mathrm{I}^{2}$ metric $(<25 \%$ low, $25 \%$ to $50 \%$ moderate, $>50 \%$ high) and its $95 \%$ CIs, if $\mathrm{I}^{2}>50 \%$, a random effects model was chosen, otherwise, fixed-effect model was applied if $\mathrm{I}^{2}<50 \%$. For continuous variables, the results were expressed as the weighted mean differences with $95 \%$ confidence interval (CIs). For all analyses, we used Review Manager 5.3 software for Windows (The Cochrane Collaboration, 2013, Oxford, United Kingdom).

\section{Results}

\subsection{Study Characteristics}

The first literature search identified 651 papers, after reading the article title and abstract, 28 of these articles were potentially eligible for the analysis, but only 11 articles could be included in the final review according to the inclusion criteria [10-20]. Analysis of the included records comprises 5171 participants, among them, 2764 adults are obese patients $(53.5 \%)$. All of these studies used conventional echocardiography to assess the left ventricular diastolic function, and more than half of the studies (6 studies) applied TDI [12-14, 16, 18-19]. All of the study designs were case-control study, mean patient age ranged from 31.1 to 70.7 years. Peak early diastolic mitral flow velocity (E),peak late diastolic mitral flow velocity (A) and E/A ratio were the most commonly reported echocardiography parameters to assess DD, deceleration time of early diastolic flow wave (DT), isovolumic relaxation time (IVRT), early diastolic myocardial velocities (Em or $\mathrm{E}^{\prime}$ ) and late diastolic myocardial velocities (Am or $A^{\prime}$ ) were reported less frequently. The main reasons for exclusion were the combination of metabolic syndrome in the obese patients (4 studies), or participants were adolescents ( 5 studies). Three studies did not provided the echocardiography data, and the included subjects had a history or examination findings of ischemic heart disease or heart failure (2 studies), or the definition of obesity based on BMI thresholds lower than 30 $\mathrm{kg} / \mathrm{m}^{2}$ (1 studies). Study characteristics are reported in Table 1. 


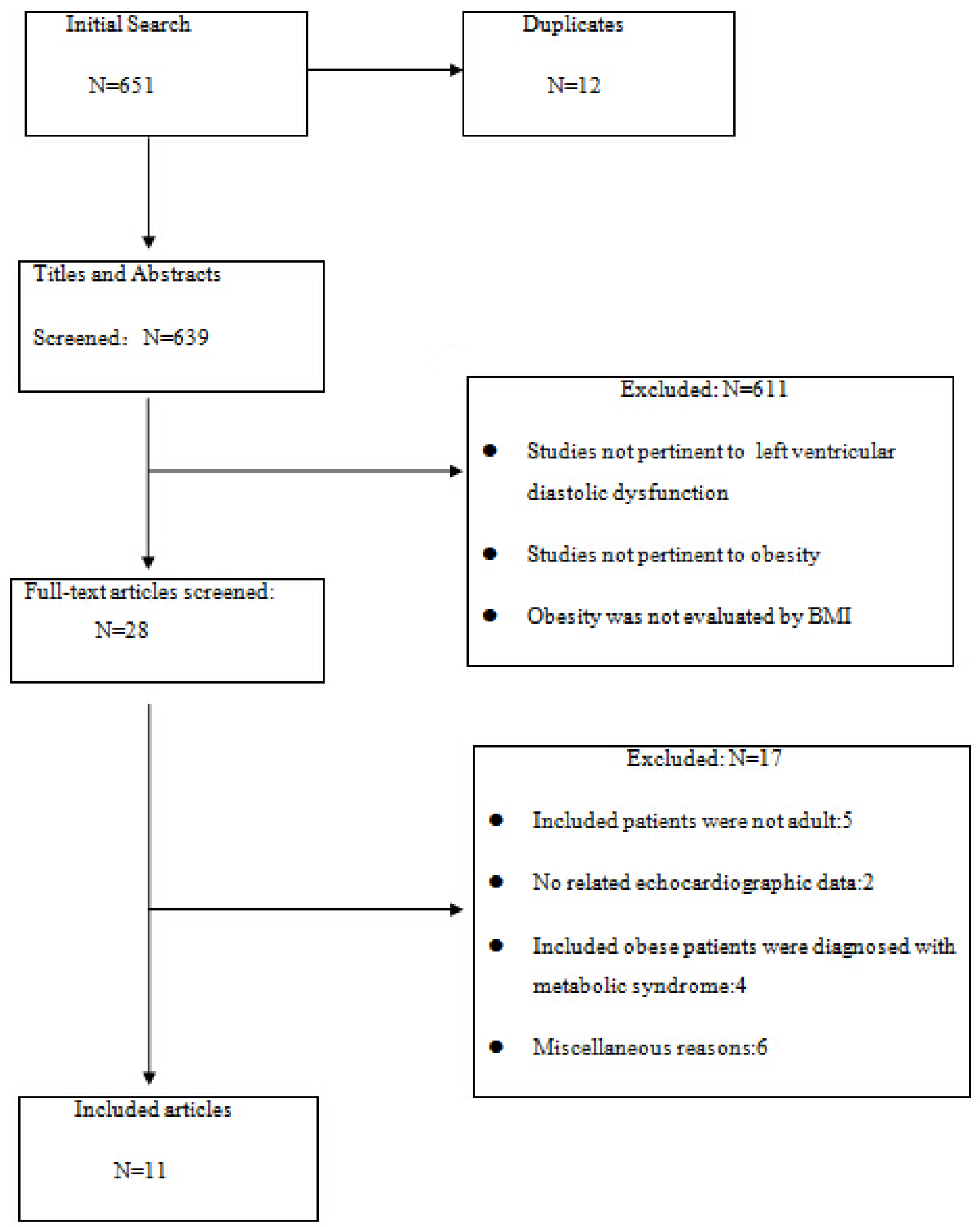

Figure 1. Flow diagram of selected studies 
Table 1. Characteristics of the studies included in the mete-analysis

\begin{tabular}{|c|c|c|c|c|c|c|c|c|}
\hline Study & Year & Country & Study Design & $\begin{array}{c}\text { Age } \\
\text { Mean(SD)y }\end{array}$ & No. & TDI & $\begin{array}{l}\text { Echocardiography Parameters } \\
\text { Related to Diastolic Function }\end{array}$ & NOS \\
\hline Berkten et al. & 1995 & Turkey & Case-control & $31.1(2.4)$ & 50 & $\mathrm{~N}$ & E,A,E/A,DT,IVRT,AC\% & 7 \\
\hline Chadha et al. & 2009 & India & Case-control & $35.2(10)$ & 42 & $\mathrm{~N}$ & $\mathrm{E}, \mathrm{A}, \mathrm{E} / \mathrm{A}, \mathrm{DT}$ & 8 \\
\hline Cil et al. & 2012 & Turkey & Case-control & $50(16)$ & 1411 & Y & E,A,E/A,DT,IVRT,E',A', E/ E' & 8 \\
\hline $\begin{array}{l}\text { Kosmala et al. } \\
\text { K }\end{array}$ & 2008 & Poland & Case-control & $41.4(13.4)$ & 241 & Y & E/A,DT, E/ E' & 8 \\
\hline Kossaify et al. & 2013 & Lebanon & Case-control & $60.5(14)$ & 151 & Y & $\mathrm{E}, \mathrm{A}, \mathrm{E} / \mathrm{A}, \mathrm{E}^{\prime}, \mathrm{E} / \mathrm{E}^{\prime}$ & 9 \\
\hline Pascual et al. & 2003 & Spain & Case-control & $30(10)$ & 73 & $\mathrm{~N}$ & E,A,E/A,IVRT, & 9 \\
\hline Perterson et al. & 2004 & America & Case-control & $31(4)$ & 51 & $\mathrm{Y}$ & E, E/A,DT,IVRT, Em/Am & 9 \\
\hline Powell et al. & 2006 & America & Case-control & $62(13)$ & 2446 & $\mathrm{~N}$ & E/A,DT & 9 \\
\hline Russo et al. & 2011 & America & Case-control & $70.7(8.9)$ & 547 & Y & $\mathrm{E}, \mathrm{A}, \mathrm{E} / \mathrm{A}, \mathrm{E}^{\prime}, \mathrm{E} / \mathrm{E}$ & 9 \\
\hline Willens et al. & 2004 & America & Case-control & $46(11.2)$ & 89 & Y & E, E/A,DT,IVRT, Em/Am & 9 \\
\hline Wong et al. & 2004 & Australia & Case-control & $46(10)$ & 70 & $\mathrm{~N}$ & E,A,E/A, IVRT,E',E/ E' & 9 \\
\hline
\end{tabular}

TDI=Tissue Doppler Imaging; E=peak early diastolic mitral flow velocity; A= peak late diastolic mitral flow velocity; DT=deceleration time of early diastolic flow wave; IVRT= isovolumic relaxation time; $\mathrm{Em}=\mathrm{E}^{\prime}=$ early diastolic myocardial velocities; $\mathrm{Am}=\mathrm{A}$ '= late diastolic myocardial velocities; NOS=Newcastle-Ottawa score

\subsection{Meta-analysis}

\subsubsection{Comparisons of $\mathrm{E}, \mathrm{A}$ and $\mathrm{E} / \mathrm{A}$ ratio between obese individuals and non-obese controls}

Peak early diastolic mitral flow velocity (E) was used to assess the left ventricular DD in 9 studies [10-12, 14-16, 18 -20]. Heterogeneity test manifested statistical heterogeneity among these studies $\left(\mathrm{I}^{2}>50 \%, P=0.0001\right)$, so random-effect model was selected. The meta-analysis of these 9 studies showed that there had no statistically significant difference of $\mathrm{E}$ in obesity group and control group $(P=0.77)$. Peak late diastolic mitral flow velocity (A) was used to assess DD in 8 studies [10-12, 14, $15,18-20]$. Heterogeneity test manifested statistical heterogeneity among these studies $\left(\mathrm{I}^{2}=59 \%, P=0.02\right)$, so random-effect model was selected. The meta-analysis of these 8 studies showed that standardized difference in means of A was higher in obesity group compared with that of in control group $(95 \% \mathrm{CI}-3.81$ to $2.82, P<0.00001)$. These data are shown in detail in Supplementary data, Figs. A and B.

Figure 2 shows the result of the meta-analysis of the association between E/A ratio and obesity. E/A ratio were used to assess DD in all of the included studies [10-20]. Heterogeneity test showed statistical heterogeneity among these studies $\left(\mathrm{I}^{2}>50 \%, P<0.00001\right)$, so random-effect model was selected. The meta-analysis of these 11 studies manifested that standardized difference in means of E/A was higher in control group compared with that of in obesity group $(95 \% \mathrm{CI}-0.78$ to $-0.32, P<0.00001)$.

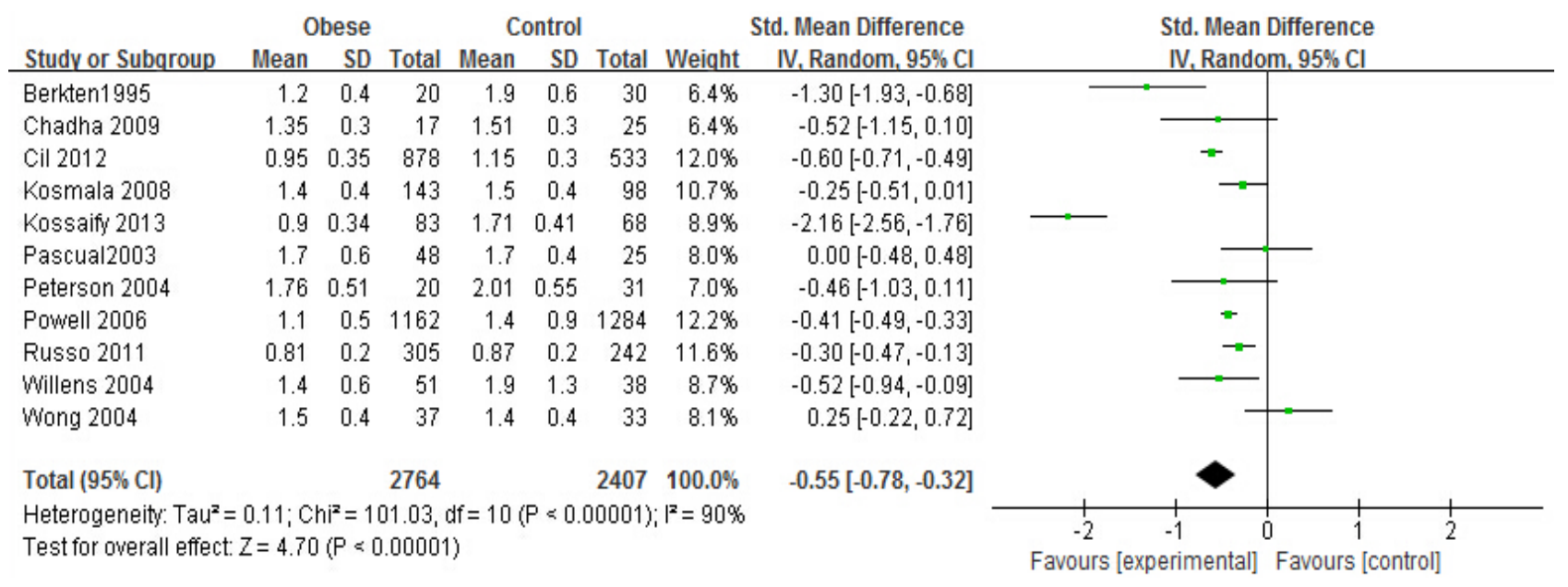

Figure 2. Forest plot of comparison for $\mathrm{E} / \mathrm{A}$

A publication bias was suggested by the presence of an asymmetric distribution of funnel plot, so we weeded out the study conducted by Kossaify and colleagues, After correction for this bias, The meta-analysis of remaining 10 studies manifested 
that E/A was also higher in control group compared with that of in obesity group $(P<0.00001)$, the results are shown in Supplementary data Fig C. Funnel plot is shown in detail in Supplementary data Fig. D.

\subsubsection{Comparison of DT between obese individuals and non-obese controls}

Deceleration time of early diastolic flow wave (DT) was applied to assess the left ventricular DD in 7 studies [10-13, 16, 17, 19]. Heterogeneity test manifested statistical heterogeneity among these studies $\left(I^{2}>50 \%, P<0.00001\right)$, so random-effect model was selected. The meta-analysis of these 7 studies showed that there had no statistically significant difference of DT in obesity group and control group $(P=0.14)$, the data are shown in Fig 3 .

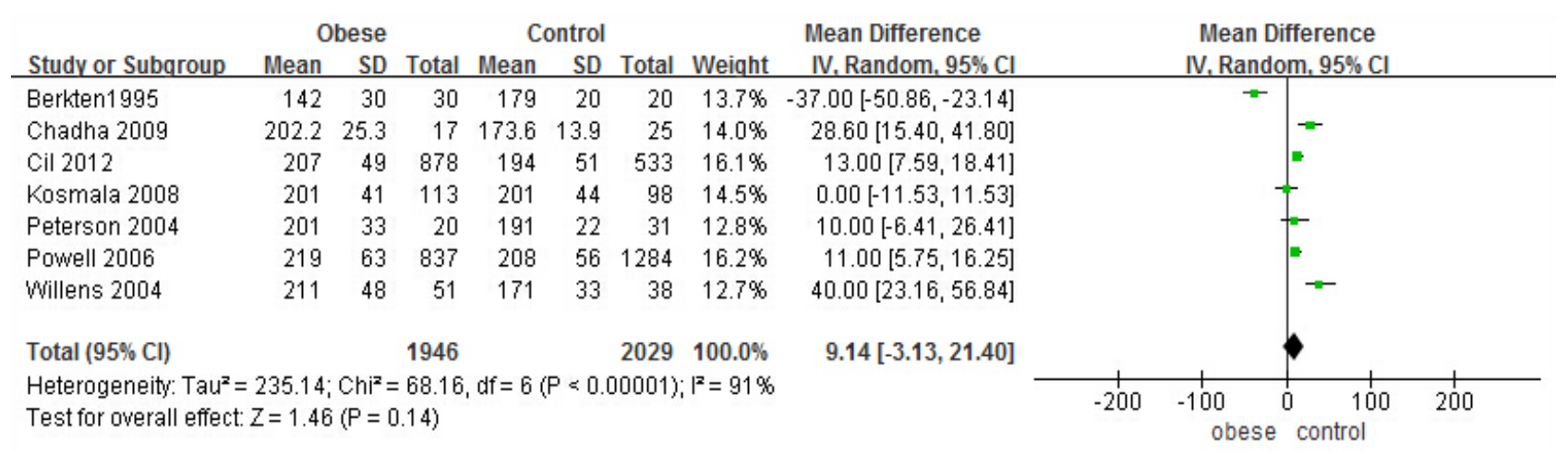

Figure 3. Forest plot of comparison for DT

\subsubsection{Comparison of IVRT between obese individuals and non-obese controls}

Isovolumic relaxation time (IVRT) was used to assess DD in 6 studies $[10,12,15,16,19,20]$. Heterogeneity test manifested statistical heterogeneity among these studies $\left(\mathrm{I}^{2}>50 \%, P<0.0001\right)$, so random-effect model was selected. The meta-analysis of these 6 studies showed that standardized difference in means of IVRT was higher in obesity group compared with that of in control group $(95 \% \mathrm{CI} 0.13-11.29, \mathrm{P}=0.04)$, the data are shown in Fig 4.

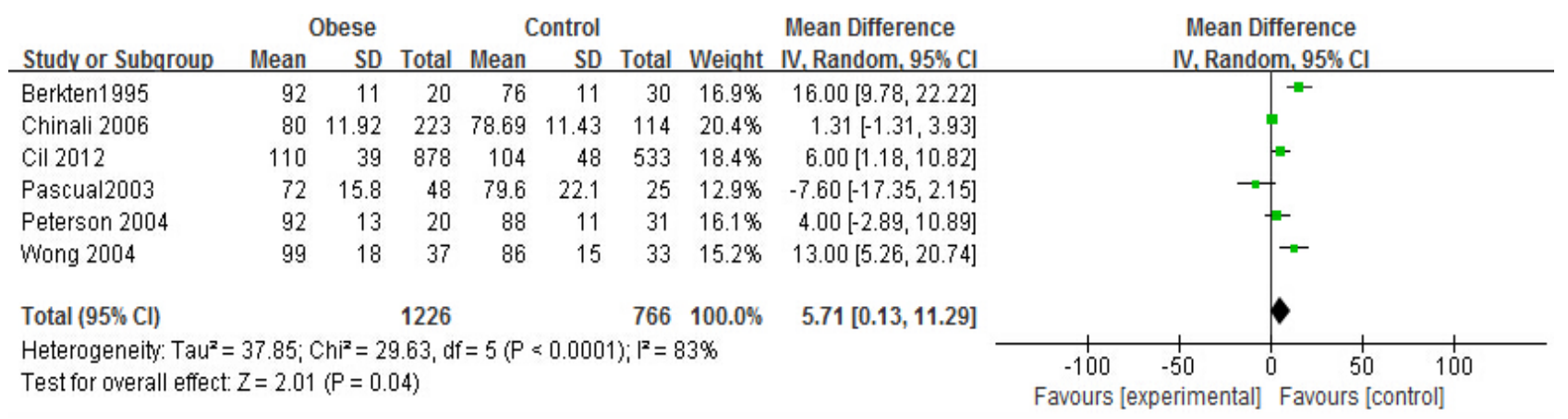

Figure 4. Forest plot of comparison for IVRT

\subsubsection{Comparison of $E^{\prime}$ between obese individuals and non-obese controls}

Early diastolic myocardial velocities (E') was used to assess the DD in 4 studies $[12,14,18,20]$. Heterogeneity test manifested statistical heterogeneity among these studies $\left(\mathrm{I}^{2}>50 \%, P<0.0001\right)$, so random-effect model was selected. The meta-analysis of these 4 studies showed that standardized difference in means of $E^{\prime}$ was lower in obesity group compared with that of in control group $(95 \% \mathrm{CI}-2.29$ to $-0.46, P=0.003)$, the data are shown in Fig 5 .

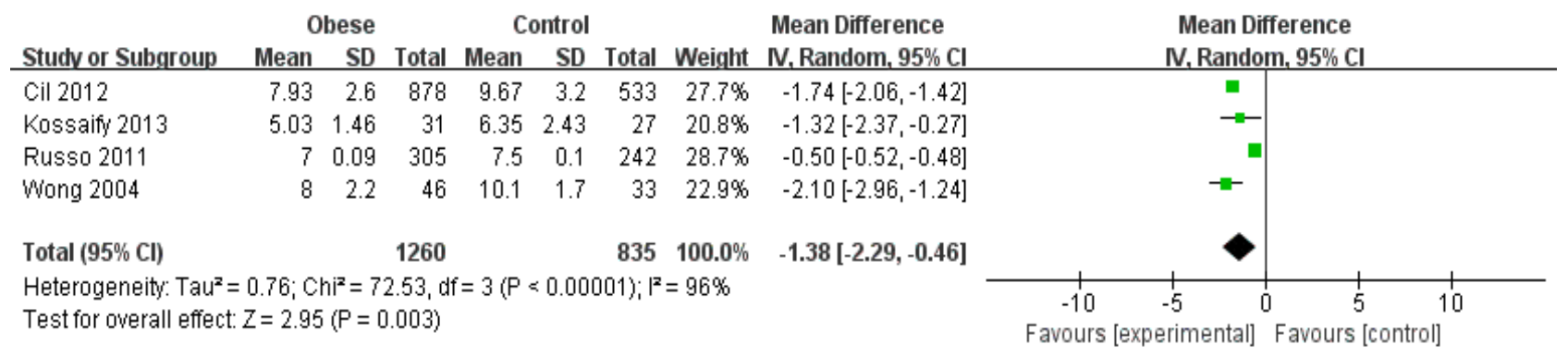

Figure 5. Forest plot of comparison for E' 


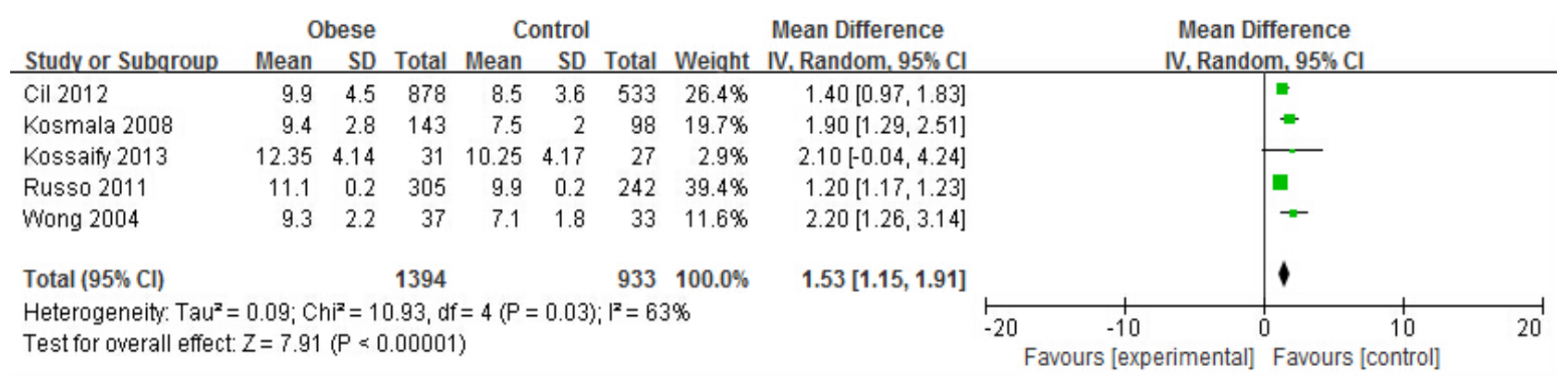

Figure 6. Forest plot of comparison for E/E'

\subsubsection{Comparison of $\mathrm{E} / \mathrm{E}$ ' ratio between obese individuals and non-obese controls}

E/E' ratio was used to assess the DD in 5 studies [12-14, 18, 20]. Heterogeneity test manifested statistical heterogeneity among these studies $\left(\mathrm{I}^{2}=63 \%, P=0.03\right)$, so random-effect model was selected. The meta-analysis of these 5 studies showed that standardized difference in means of $\mathrm{E} / \mathrm{E}^{\prime}$ was higher in obesity group compared with that of in control group $(95 \% \mathrm{CI} 1.15-1.91, P<0.00001)$, the data are shown in Fig 6.

\section{Discussion}

As a major health issue, the prevalence of obesity is steadily increasing both in the developed and developing world [21]. Obesity is associated with diabetes mellitus, hypertension and increased cardiovascular morbidity and mortality [22], especially it is an independent predictor of future development of heart failure [23]. DD is a condition that reflects an impairment of the filling properties of the left ventricle, and it might represent the pathophysiological links between obesity and the future occurrence of heart failure [24].

The potential articles were selected strictly according to the Newcastle-Ottawa quality assessment scale. All the included studies are case-control study, these studies had a Newcastle-Ottawa score of seven or more (more than six), which indicates the high level of evidence in present meta-analysis. In order to control the effects of confounding factors, present study did not include the object combined with metabolic syndrome, coronary heart disease and high blood pressure. In order to evaluate the severity of obesity, index such as BMI, waist circumference (WC), waist-to-hip ratio (WHR), waist-to-height ratio are often used, BMI is most widely used as universal standard among these index [25]. For this reason, we adopted $B M I \geq 30 \mathrm{~kg} / \mathrm{m}^{2}$ as a standard definition of obesity. There have been several studies evaluating DD in obese adult manifested that it has been correlated with BMI, and the relationship between BMI and diastolic function parameters is continuous, parameters related to DD are getting worse with the increasing BMI, while these findings were inconsistent $[5,6,7]$.

There are several conventional parameters to assess the DD, such as E, A, E/A ratio, DT, IVRT, which are measured by traditional Doppler. Important diastolic function parameters were not included in all the studies, however, all of the included researches used traditional Doppler to measure E/A ratio because it is an important marker of ventricular diastolic function, while the other parameters such as DT, IVRT were not measured in all the included studies. As a highly sensitive and specific echocardiographic technique, TDI established the gold diagnostic criteria in the assessment of diastolic function because it is relatively load-independent [26], and this is very important in the setting of heart failure when loading parameters are usually disturbed, $E^{\prime}$ and $E / E^{\prime}$ ratio are the important measurement in TDI, and E/E' ratio can be used as an index of left ventricular filling pressures, also it is significantly correlated with mean pulmonary capillary wedge pressure (PCWP) [27]. In this meta-analysis, more than half of the included studies (6 studies) used TDI to assess cardiac structure and function.

The present systematic review of 11 studies published in the past 20 years provides updated information on the DD and obesity in different clinical settings. To the best of our knowledge, our paper is the first largest-scale meta-analysis study in the literature which evaluates the correlation between BMI and DD in the general population. Meta-analysis of selected 11 studies (2764 obesity subjects and 2407 normal weight) we found that obesity was associated with DD. Although there is no difference of A and DT between the two groups, other related parameters such as $\mathrm{A}, \mathrm{E} / \mathrm{A}$ ratio, IVRT, E' and E/E' ratio are significant different between obese individuals and non-obese controls, the values of $\mathrm{A}$, IVRT and E/E' were higher in obesity group compared with that of in control group, while the values of E/A ratio and E' were lower in obesity group. Random-effect model was selected in all the meta-analysis because there were statistical heterogeneity among these studies $\left(\mathrm{I}^{2}>50 \%\right)$.

Obesity may contribute to the development and progression of DD by multiple mechanisms. The possible mechanism might be associated with the fact that long-term volume overload leads to the increasing myocardial oxygen consumption and compensatory left ventricular hypertrophy [28]. The excess of adiposity is recognized as an active endocrine organ secreting many important metabolic and hormonal molecules including pro-inflammatory cytokines, another option could be that angiotensin II is up regulated by cytokines in the pro-inflammatory condition of obesity, which contributes to myocardial tissue growth and fibrosis 
[29]. The last but not the least possibility might be hyperinsulinemia caused by insulin resistance [30], it is major condition linking metabolic abnormalities and impairment of left ventricular diastolic function in obesity, effects of insulin on myocytes and interstitial fibrosis may contribute to increased left ventricular wall stress and cardiac myocyte apoptosis, then leading to subclinical elevated left ventricle diastolic filling pressure. These changes lead to the filling impairment and DD.

There are several limitations in the present study: First, this is a meta-analysis of observational studies, there was an obvious heterogeneity between these studies for the reason of bias. For example, more than half of the studies enrolled the young healthy adults $[10,11,13,15,16,19,20]$, while some of the studies enrolled the aged ( $>60$ years) $[14,17,18]$. Age, female, hypertension are recognized as predisposing factors for $\mathrm{DD}$, although the object of study excluded the patients with coronary heart disease (CHD), left ventricular diastolic function of older people tend to influenced by co-morbid conditions such as hypertension, diabetes mellitus and obstructive sleep apnea. Secondly, selected gender differences may also be one of the cause of poor homogeneity, Peterson et al [16] included only women as research subjects. In addition, investigation of the subgroup analyses of the overweight $\left(\mathrm{BMI} \geq 25 \mathrm{~kg} / \mathrm{m}^{2}\right)$ and extremely obese $\left(\mathrm{BMI} \geq 40 \mathrm{~kg} / \mathrm{m}^{2}\right)$ subjects were not performed in the present study.

DD contributes to the future development of heart failure. The significance of this study is to confirm the evidence that obesity is associated with $\mathrm{DD}$, and provide a new point of view for early prevention and treatment of chronic heart failure: it will be interesting to evaluate whether significant weight loss may indeed reverse DD, weight control may be an important strategy to prevent and control heart failure [31].

\section{Acknowledgements}

Equal contributions were made to this article by Dr Luo Liyun and Dr Li Songbiao.

Corresponding Author: Dr Lin Xiufang

\section{Conflicts of Interest}

The authors report no conflicts of interest. The authors alone are responsible for the content and writing of the paper.

\section{REFERENCES}

[1] Wang TJ. The obesity paradox in heart failure: weighing the evidence. J Am Coll Cardiol 2014; 64(25):2750-2.

[2] Eckel RH, York DA, Rössner S, Hubbard V. Prevention
Conference VII: Obesity, a worldwide epidemic related to heart disease and stroke: executive summary. Circulation 2004; 110(18):2968-75.

[3] Takiguchi M, Yoshihisa A, Miura S, Shimizu T, Nakamura $\mathrm{Y}$, Yamauchi $\mathrm{H}$, Iwaya S, et al. Impact of body mass index on mortality in heart failure patients. Eur J Clin Invest 2014; 44(12):1197-205.

[4] Lavie CJ, Alpert MA, Arena R, Mehra MR, Milani RV, Ventura HO. Impact of obesity and the obesity paradox on prevalence and prognosis in heart failure. JACC Heart Fail 2013; 1(2):93-102.

[5] Canepa M, Strait JB, Abramov D, Milaneschi Y, AlGhatrif M, Moni M. Contribution of central adiposity to left ventricular diastolic function (from the Baltimore Longitudinal Study of Aging). Am J Cardiol 2012; 109(8):1171-8.

[6] Kishi S, Armstrong AC, Gidding SS, Colangelo LA, Venkatesh B. Association of obesity in early adulthood and middle age with incipient left ventricular dysfunction and structural remodeling: the CARDIA study (Coronary Artery Risk Development in Young Adults). JACC Heart Fail 2014; 2(5):500-8.

[7] Libhaber CD, Norton GR, Majane OH, Libhaber E, Essop MR. Contribution of central and general adiposity to abnormal left ventricular diastolic function in a community sample with a high prevalence of obesity. Am J Cardiol 2009; 104(11):1527-33.

[8] Wells GA, Shea B, Higgins JP, Sterne J, Tugwell P, Reeves BC. Checklists of methodological issues for review authors to consider when including non-randomized studies in systematic reviews. Res Synth Methods 2013; 4(1):63-77.

[9] Moher D, Liberati A, Tetzlaff J, Altman DG; PRISMA Group. Preferred reporting items for systematic reviews and meta-analyses: the PRISMA statement. PLoS Med 2009; 6(7):e1000097.

[10] Berkalp B, Cesur V, Corapcioglu D, Erol C, Baskal N. Obesity and left ventricular diastolic dysfunction. Int $\mathrm{J}$ Cardiol 1995; 52(1):23-6.

[11] Cil H, Bulur S, Türker Y. Impact of Body Mass Index on Left Ventricular Diastolic Dysfunction. Echocardiography 2012, Apr 4 (Epub ahead of print).

[12] Wg Cdr DS Chadha, Wg Cdr A Swamy, Col SK Malani. Impact of Body Mass Index on Left Ventricular Function. MJAFI 2009; 65:203-207.

[13] Kosmala W1,Wong C, Kuliczkowska J, Leano R, Przewlocka Kosmala M, Marwick TH. Use of body weight and insulin resistance to select obese patients for echocardiographic assessment of subclinical left ventricular dysfunction. Am J Cardiol 2008; 101(9):1334-40.

[14] Kossaify A, Nicolas N. Impact of overweight and obesity on left ventricular diastolic function and value of tissue Doppler echocardiography. Clin Med Insights Cardiol 2013; 7:43-50.

[15] Pascual M, Pascual DA, Soria F, Vicente T, Hernández AM, Tébar FJ, et al. Effects of isolated obesity on systolic and diastolic left ventricular function. Heart 2003; 89 (10):1152-6.

[16] Peterson LR, Waggoner AD, Schechtman KB, Meyer T, Gropler R J, Barzilai B, et al. Alterations in left ventricular 
structure and function in young healthy obese women: assessment by echocardiography and tissue Doppler imaging. J Am Coll Cardiol 2004; 43(8):1399-404.

[17] Powell BD, Redfield MM, Bybee KA, Freeman WK, Rihal CS. Association of obesity with left ventricular remodeling and diastolic dysfunction in patients without coronary artery disease. Am J Cardiol 2006; 98(1):116-20.

[18] Russo C, Jin Z, Homma S. Effect of diabetes and hypertension on left ventricular diastolic function in a high-risk population without evidence of heart disease. Eur $\mathbf{J}$ Heart Fail 2010; 12:454-61.

[19] Willens HJ, Chakko SC, Lowery MH, Byers P, Labrador E, Gallagher A, et al. Tissue Doppler imaging of the right and left ventricle in severe obesity (body mass index $>35 \mathrm{~kg} / \mathrm{m}^{2}$ ). Am J Cardiol 2004; 94(8):1087-90.

[20] Wong CY1,O'Moore-Sullivan T, Leano R, Byrne N, Beller E, Marwick TH. Alterations of left ventricular myocardial characteristics associated with obesity. Circulation 2004; 110(19):3081-7.

[21] Prospective Studies Collaboration, Whitlock G, Lewington S, Sherliker P, Clarke R, Emberson J, Halsey J, et al. Body-mass index and cause-specific mortality in 900000 adults: collaborative analyses of 57 prospective studies. Lancet 2009; 373(9669):1083-96.

[22] Murphy NF, MacIntyre K, Stewart S, Hart CL, Hole D, McMurray JJ. Long-term cardiovascular consequences of obesity: 20-year follow-up of more than 15000 middle-aged men and women (the Renfrew-Paisley study). Eur Heart J 2006; 27(1):96-106.

[23] Loehr LR, Rosamond WD, Poole C, McNeill AM, Chang PP, Folsom AR, et al. Association of multiple anthropometrics of overweight and obesity with incident heart failure: the Atherosclerosis Risk in Communities study. Circ Heart Fail
2009; 2(1):18-24.

[24] Turkbey EB1, McClelland RL, Kronmal RA, Burke GL. The impact of obesity on the left ventricle: the Multi-Ethnic Study of Atherosclerosis (MESA). JACC Cardiovasc Imaging 2010; 3(3):266-74.

[25] Amy Berrington de Gonzalez, Patricia Hartge, James R. Body-Mass Index and Mortality among 1.46 Million White Adults. N Engl J Med 2010; 363(23): 2211-2219.

[26] Nagueh SF, Middleton KJ, Kopelen HA, Zoghbi WA, Quiñones MA. Doppler tissue imaging: a noninvasive technique for evaluation of left ventricular relaxation and estimation of filling pressures. J Am Coll Cardiol 1997; 30(6):1527-33.

[27] Sharp AS,Tapp RJ, Thom SA, Francis DP, Hughes AD. Tissue Doppler E/E' ratio is a powerful predictor of primary cardiac events in a hypertensive population: an ASCOT sub study. Eur Heart J 2010; 31(6):747-52.

[28] Alpert MA and Hashimi MW. Obesity and the heart. Am J Med Sci 1993; 306 (2):117-23.

[29] Pacholczyk M, Ferenc T, Kowalski J, Adamczyk P, Chojnowski J, Ponikowska I. Association of angiotensin-converting enzyme and angiotensin II type I receptor gene polymorphisms with extreme obesity in Polish individuals. DNA Cell Biol 2013; 32 (8):435-42.

[30] Peterson LR, Herrero P, Schechtman KB, Racette SB, Waggoner AD. Effect of obesity and insulin resistance on myocardial substrate metabolism and efficiency in young women. Circulation 2004; 109 (18):2191-6.

[31] Fenk S1, Fischer M, Strack C, Schmitz G, Loew T, Lahmann C. Successful weight reduction improves left ventricular diastolic function and physical performance in severe obesity. Int Heart J 2015; 56(2):196-202. 